\title{
La Ejecutoria de Hidalguía de don Alonso de Herrera, un manuscrito ilustrado en la época de Felipe II
}

\author{
Francisco SANZ FERNÁNDEZ \\ Universidad de Extremadura
}

RESUMEN. Las Ejecutorias de Hidalguía fueron documentos de carácter público en los que se reconocía o rebatía una merced secular a una familia o linaje. Debido al valor que estos documentos adquirían para sus destinatarios, en cuanto símbolos de un statu quo que estaban obligados a mantener, fueron iluminados en forma de lujosos libros: muchos de ellos en talleres cercanos o inmediatos a las ciudades de Granada y Valladolid, donde se hallaban las reales chancillerías, en que se dirimían este tipo de pleitos.

La Ejecutoria de Hidalguía de don Alonso de Herrera, es uno de estos documentos de finales del Renacimiento que fue iluminado con ricas miniaturas, elegante letra libraria y encuadernado en piel exornada con decoraciones a fuego.

Se trata de uno de los documentos más interesantes de la época hallado entre los fondos archivísticos privados de la ciudad altoextremeña de Trujillo: uno de los focos artísticos más importantes del Renacimiento español.

Palabras clave: ejecutorias de hidalguía, miniatura, Renacimiento, Trujillo.

ABSTRACT. The Executorships of Nobility were documents of public character in which a secular mercy was recognizing or refuting to a family or lineage. Due to the value that these documents were acquiring for his addressees, in symbols of a statu quo that were forced to support, they were illuminated in the shape of luxurious books: many of them in nearby or immediate workshops to the cities of Granada and Valladolid, where there were situated the royal chancelleries, in which this type of lawsuits were dissolved.

The Executorships' of Don Alonso de Herrera, it is one of these documents of ends of the Renaissance that was illuminated by rich miniatures, elegant letter libraria and bound in leather adorned by decorations to fire.

It is a question of one of the most interesting documents of the epoch found between the funds archivist deprived of the city altoextremeña of Trujillo: one of the most important artistic areas of the Spanish Renaissance.

Key words: executorships of nobility, miniature, Renaissance, Trujillo.

\section{REAL CHANCILLERÍA DE GRA- NADA \\ Granada. 11 de julio de 1588 - 9 de junio de 1592.}

Carta Ejecutoria de Hidalguía a pedimento de Alonso de Herrera, vecino del lugar de Robledillo, jurisdicción de la ciudad de Trujillo.

Códice.
Vitela. $310 \times 210 \times 30 \mathrm{~mm}, 48$ folios sin numeración, 34 líneas.

Letra libraria del s. XVI.

Encuadernación en piel con decoración floral incisa "en blanco" y piñas pinjantes, conchas y Cordero Místico en oro.

Archivo particular de la familia Sanz Gutiérrez. Trujillo (Cáceres). 
Las Ejecutorias de Hidalguía, como los Privilegios, fueron documentos de carácter público en los que se reconocía o rebatía, tras un tedioso y prolongado enfrentamiento jurídico entre un supuesto hidalgo, cuyo solar y linaje se discutían, y los distintos órganos de control y gobierno del complejo aparato burocrático de la corona española, o entre un municipio y la corona, una merced secular, cuyo fin último no era otro que procurar un beneficio económico a sus receptores ${ }^{1}$. Debido al valor que estos documentos adquirían para sus destinatarios, en cuanto símbolos de un statu quo que estaban obligados a mantener - particularmente en aquellos casos donde la sentencia última les era favorable-, a lo largo de los reinados de Carlos V, Felipe II y Felipe III, fueron iluminados en forma de lujosos libros. Libros encuadernados en piel de cabra, cerdo o ternero. Todo con la finalidad de exhibirlos y dejar así constancia de la condición de hombres no pecheros, esto es, eximidos de pagar impuestos, y de solar muy antiguo de sus promotores.

Las Ejecutorias de Hidalguía iluminadas son, por tanto, obras con valor artístico, jurídico, sociológico e histórico que derivan de la necesidad de autoafirmación de un linaje, es decir, de la constatación y antigüedad de su solar, y de la voluntad evasora del pago de pechos. A partir de esta definición, resulta fácil entender, dada la cantidad de hijosdalgos ${ }^{2}$ que habitaban la

\footnotetext{
${ }^{1}$ R. MARCHENA HIDALGO, «La iluminación de privilegios y ejecutorias: entre el arte cortesano y el arte local», IX Jornadas de Arte, El arte en las cortes de Carlos $V$ y Felipe II, Departamento de Historia del Arte "Diego Velázquez", Centro de Estudios Históricos (C.S.I.C.), Madrid, 1999, p. 125.

${ }^{2}$ Muchos de ellos víctimas de la hambruna, pestes y devaluaciones monetarias que ampliamente recogieron no pocos textos contemporáneos - pensemos en algunos de los sucesos de El Lazarillo de Tormes o, ya con posterioridad, de El Quijote y de la Relación oficial del Viaje por España y Portugal del Príncipe Cosme III de Médicis escrito por Lorenzo Magalotti —. Véanse:
}

ya decadente España de los últimos años del reinado de Felipe II, bajo cuyo reinado se iluminó el códice objeto de nuestro interés, que la baja nobleza volcase sus esfuerzos por mantener su tesoro más preciado y el de sus descendientes: la exención de tributos. Y por ello, que fuesen muchos y numerosos los casos pleiteados en las Chancillerías de Granada y Valladolid que dieron lugar, una vez resueltos en grado de apelación y suplicación, a una producción seriada y homogénea de textos iluminados, donde se repetían toda una serie de pautas que alcanzaban a las dimensiones del códice -que varían sin excepción entre $210 \mathrm{x}$ $335 \mathrm{~mm}-$, su temática -imágenes, formas, disposición y contenidos-, tipo de letra, o, por supuesto, fórmulas jurídicas del texto. Éstas últimas directamente vinculadas al proceso artístico, pues, como puede comprobarse en los folios 26v., 34v., 39v., 43r. y 44r. de la Ejecutoria de Hidalguía de Alonso de Herrera, las declaraciones de los testigos quedaban siempre encabezadas por una capital con forma vegetal o arquitectónica ricamente ornamentada con rojo de minio, bermellón, oro y azurita.

$\mathrm{Al}$ margen de este resultado final que era el códice iluminado, hoy infravalorado desde toda perspectiva sociológica, podrían considerarse pues no pocas lecturas transversales, entre las que cabrían reseñarse: la cantidad de datos que aportan sobre los orígenes y miembros del linaje o los testigos a que se refieren las páginas del documento - lugar de procedencia, apellidos, edad, descendientes, ocupaciones-, así como acerca del funcionamiento de los órganos

\footnotetext{
AA.VV., El viaje a Compostela de Cosme III de Médicis, Xunta de Galicia, Salamanca, 2004; y Mà. M. LOZANO BARTOLOZZI, «Miradas urbanas de la Baja Extremadura en el siglo XVII. El viaje del Príncipe Cosme de Médicis», en Estudio sobre la Historia de Zafra y el Estado de Feria, Cuadernos de Zafra, no IV, Zafra, 2006, pp. 3164.
} 
civiles de administración de la justicia en tiempos de los Austrias.

Desde esta perspectiva, el códice de Alonso de Herrera nos permite conocer los nombres de una decena de vecinos de distinta condición del lugar de Robledillo, una pequeña población de la penillanura trujillano-cacereña constituida en concejo y ocupada mayoritariamente por población no pechera, ya con anterioridad al reinado de los RR. CC. ${ }^{3}$. Algunos de estos nombres son: los de Juana García, Álvaro de Torres, hijodalgo, y Antón de Marta, labrador: "hombre llano pechero, que dijo conocer a Alonso de Herrera desde su niñez". Asimismo cabría citar in extensus: a Juan de Chaves, caballero hijodalgo, Corregidor de la ciudad de Córdoba, de sesenta y dos años, quien dijo "le conoscía [a Alonso de Herrera] mastiempo de treynta años porque le conoscia niño pequeño y mancebo"; así como al Doctor Paz de Heredia y a don Francisco Mena de Barnuevo, fiscales de Su Majestad. Añadamos también los nombres de Gonzalo Muñoz de Castilblanquez, Escribano Receptor de la Audiencia de Granada, o de Baltasar García Altamirano y Francisco de Aguilera, procuradores de ambas partes, que se desplazaron, entre otros lugares, a las citadas localidades de Córdoba y Robledillo para tomar testimonio y juramento a los testigos susodichos, por ser éstos de avanzada edad.

\section{DESCRIPCIÓN CODICOLÓGICA.}

Al margen de esta rica información, bien es cierto de menor interés para nosotros, dada nuestra voluntad prioritaria de análisis artístico del códice, la Ejecutoria de Hidalguía de Alonso de Herrera, Becerra y Carvajal, según se desprende de la heráldi-

\section{-}

${ }^{3}$ Ma A. SÁNCHEZ RUBiO, «Trujillo y su tierra en la Baja Edad Media. Relaciones de poder y dominio», en La Tierra de Trujillo: desde la época Prerromana a la Baja Edad Media, Real Academia de Extremadura de las Letras y las Artes, Badajoz, 2005, pp. 169-ss. ca que acompaña la miniatura del folio $2 \mathrm{v}$., queda recogida en un códice encuadernado en piel de ternero de unos tres centímetros de grosor que ornamentan una rica y ordenada figuración de motivos vegetales, vieiras y corderos místicos dorados sobre un fondo hecho en su mayor parte a fuego, donde aún son perceptibles, por tanto, algunas modalidades bajo medievales y renacentistas propias de los talleres de encuadernación hispanos de la segunda mitad del siglo $\mathrm{XVI}^{4}$. El frontispicio queda organizado por dos bandas rectangulares hechas con ruedecilla y ornamentadas con motivos vegetales ordenados a candelieri "en blan$\mathrm{Co}^{\prime \prime}$, ésto es sin dorar, sobre las que se disponen simétricamente: hacia el exterior, en cada extremo, una representación del Cordero Místico nimbado que porta cruz con gallardete; bajo éstos, sendas vieiras afrontadas; dos óvalos; $\mathrm{y}$, en el centro, dos pirámides herrerianas o serlianas enfrentadas por la base. Hacia el interior, organizando el alma, cuatro florones pinjantes esquinados; cuatro nuevas representaciones del Cordero Místico; y, en el centro, una estrella de ocho puntas flaqueada por cuatro conchas de Santiago y una última imagen de Cristo bajo la forma simbólica del Cordero. Cinco hilos de seda roja y verde, una por cada lado menor y tres en los mayores, hoy muy deteriorados, servían de cierre a todo el conjunto.

El interior, formado por cuarenta $y$ ocho páginas de vitela sin numerar, comienza con un folio en blanco firmado por Alonso de Cuenca y Diego de Torres, bajo cuyas rúbricas puede leerse "dos mill cuatrocientos y nobenta mrs 7 rro sello en seda y plomo".

El folio siguiente (2v.), precedido de una fina lámina de seda roja que protegía

\footnotetext{
${ }^{4}$ J. AINAUD, Encuadernación, Col. Ars Hispaniae, Vol. XVIII, Plus-Ultra, Madrid, 1962, p. 330.
} 
las miniaturas, constituye sin duda una de las páginas de mayor valor artístico de todo el documento, dado que se trata de una iluminación a toda página organizada dentro de un rectángulo con triple bordura hecha en negro carbón y oro $(4 \mathrm{~mm}$.), en cuyo interior se disponen dos grandes orlas, una por cada extremo ( $30 \mathrm{~mm}$.), decoradas con motivos florales ordenados en forma de roleos o de candelieri, y angelotes. En la parte superior de cada una de éstas, entre cartelas rectangulares, se alojan, a modo de grisallas -iluminadas en negro y oro-, dos imágenes de devoción nimbada en forma de efigies: un San Pedro, acompañado de su correspondiente atributo, las llaves; y una Santa Bárbara, también portadora de su atributo habitual, un cáliz o copón. Ya en el centro de la página, de arriba abajo, podemos ver: una miniatura organizada bajo la geometría de una estructura piramidal -donantes y Virgen de la Rosa con Niño - inserta en un cuadrado de $130 \mathrm{x}$ $130 \mathrm{~mm}$.; una cartela sobre fondo azurita, donde puede leerse escrito en oro [DONPHI * LIPPE], en clara alusión a Felipe II; y una última iluminación, el escudo de armas de don Alonso de Herrera, cuartelado, entre otras, con las armas de los Herrera - de gules, dos calderos de sable al palo y bordura cosida cargada de doce calderas de sable-, Becerra - de sinople, dos becerros de oro colocados al palo- y Carvajal - de oro, banda de sable ${ }^{5}$; t todo el conjunto timbrado de una celada con cinco penachos, de lambrequines y acolado de una cartela.

Ya en el folio 3r., siguiendo el esquema compositivo de obras coetáneas salidas de los talleres de Valladolid o de lugares cercanos a donde residió la corte (Monzón, Madrid, El Pardo, Uclés) como la Ejecutoria de Juan de Ávila el Viejo del Museo

\footnotetext{
${ }^{5}$ P. CORDERO AlvarAdo, Trujillo, guía monumental y heráldica, María Maestre, Cáceres, 1996, pp. 208-213.
}

de Bellas Artes de Sevilla ${ }^{6}$ o la Sentencia y Carta Ejecutoria del bachiller Pedro de Torres del Convento de San Pedro de Medina de Pomar (Burgos) ${ }^{7}$, encontramos una segunda miniatura ordenada bajo una orla (20 mm.), ahora sí desarrollada en los cuatro lados del folio, que reproduce, sobre un fondo de oro, una abundante decoración de elementos vegetales, trasunto renacentista de las viejas marginalias, en verde, rojo, azul y negro. Ornamentación que recuerda a la del folio 2 de la citada Ejecutoria de Juan de Ávila el $V i e j o{ }^{8}$. Cada una de las esquinas de la orla la ocupa un círculo iluminado con azurita y decoración geométrica de oro, inserto en un cuadrado también de oro.

En el interior de esta última página, hallamos una miniatura de $97 \times 90 \mathrm{~mm}$ que reproduce el conocido grabado de Schongauer del Apóstol sobre caballo en corbeta con la mano derecha alzada y con espada en actitud de ataque. Se trata de una estampa reproducida reiteradamente en vidrieras, pinturas de gran formato y no pocos libros de coro, según señala Rosario Marchena, desde los años finales del siglo $X V$. No obstante, a diferencia del grabado del artista de Colmar, y debido a la reformulación del modelo hecha por Tiziano para los retratos ecuestres, Santiago fue

\footnotetext{
${ }^{6}$ R. MARCHENA HIDALGO, «La iluminación de privilegios...», art. cit., p. 129.

${ }^{7}$ N. LÓPEZ MARTín, «Los Reyes en su corte», en Los Libros y documentos en la Iglesia de Castilla y León, (Exposición «Las Edades del Hombre», Burgos, 1990), Valladolid, 1990, pp. 126-127 (ficha no 66).

${ }^{8}$ Véanse también las orlas del Libro de Visita de 1602 regalado a Felipe III por la Universidad de Alcalá de Henares, "Conocida -en relación con el libro artísticopor patrocinar en sus primeros tiempos impresiones en las que las orlas y demás grabados decorativos anticipan, en cierto modo, la llegada y difusión de algunos modelos de decoraciones a la italiana orladas con bandas amplias pobladas de plantas y una variada fauna". R. GONZÁLEZ RAMOS, «Los libros minados que la Universidad de Alcalá regaló a Felipe III: adulación y comunicación mediante el libro con imágenes», en Libros con arte, Arte con libros, Cáceres, 2007, 401-ss.
} 
representado por el anónimo artista que ejecutó las miniaturas vestido con armadura, tocado con morrión y adornado de una capa bermellón perfilada de oro; modelo que podemos contemplar también en el folio 5 de la Ejecutoria de Francisco de la Peñuela Piedrola reproducido por la citada Rosario Marchena o en el Privilegio de Felipe II sobre la real audiencia de Galicia custodiado en el Archivo de la Catedral de Santiago de Compostela.

A la derecha de esta miniatura, bajo un fondo azurita y bermellón, puede leerse en letras de oro [POR/LAGRA/ CIADE/ DIOS].

En los folios siguientes, rayados con paralelas horizontales de color azul que sirvieron de plantilla a un desconocido pendolista, se suceden: a modo de encabezamiento, los títulos de Su Majestad Felipe II, $y$, tras éstos, los preceptivos formularios jurídicos de toda Ejecutoria encabezados por sencillas capitales ejecutadas a pluma con tinta negra. Ya en el folio $8 \mathrm{v}$., una vez comienzan los interrogatorios de los testigos, aparecen las primera capitales ricamente ornamentadas, siempre elaboradas en oro sobre un fondo decorado con hojas entrelazadas en forma de roleos, que varía del bermellón, al sombra o la azurita. Así podemos encontrarlas en los folios $12 \mathrm{r}$. ("A"); 19v. ("A"); 26v. ("I"); 34 v. ("E" y “F”); 39v. (“E” y “F”); 43r. (“E” y “F”); y 44r. ("P"). Ésta última capital muestra dentro del ductus un retrato del "piadosísimo y religiosísimo" Felipe II, como lo calificara el veneciano Tomás Contarini, según era costumbre tanto en la iluminación de ejecutorias, cuanto de privilegios reales. Reiteración que, según se comprueba en la Real Cédula de Felipe II sobre la jurisdicción y alcabalas de varias villas de la tierra de 1570 o en

\footnotetext{
${ }^{9}$ R. MARCHENA HIDALGO, «La iluminación de privilegios...», art. cit., p. 132.
}

la Ejecutoria de Hidalguía de Francisco Salido de Alcoba de $1592^{10}$, sirvió para difundir y consolidar, dado el carácter más que realista de los rasgos del monarca, una iconografía real apoyada, en no pocos casos, de ciertos convencionalismos como el cetro o la armadura de filetes de oro decorada "al romano"; heredada del Augusto de Prima Porta o del busto de Cosme I de Médicis de Cellini.

Por último, la Ejecutoria termina en el folio 48 con las firmas de los licenciados Diego Mejías de Feria, Diego Lucio Lucero y Alonso de Grado, así como con la del Escribano Mayor de los Alcaldes de Hijosdalgos de la Chancillería de Granada, Blas de Varela.

\section{ESTUDIO ARTÍSTICO DE LA EJECUTO- RIA.}

De lo dicho hasta el momento podemos deducir que la Ejecutoria de Alonso de Herrera se ajusta a las modelos de ejecutorias expedidos en las chancillerías oficiales repitiendo una serie de fórmulas que dejan poco margen a la libertad de composición, como orlas florales, retrato orante del beneficiario con su familia e imágenes sacras y alegóricas. Así mismo, que su iluminador siguió los tipos estilísticos propios de los talleres hispanos de la segunda mitad del siglo XVI, donde las fórmulas flamencas, incorporadas desde las últimas décadas del cuatrocientos a través de estampas y libros impresos en talleres alemanes o españoles de Zaragoza, Toledo o Sevilla ${ }^{11}$, conviven todavía con el estilo "al romano", palpable, según se concretará en las próximas pági-

\footnotetext{
${ }^{10}$ Ibidem.

11 A este respecto, véanse: J. GARCÍA VEGA, El grabado del libro español. Siglos XV-XVI-XVII, Valladolid, 1984; C. FAULHABER, Libros y bibliotecas en la España medieval, Valencia, 1987; C. LACARRA DUCAY, «Influencia de Schongauer en los primitivos aragoneses», Boletín del Museo e Instituto Camón Aznar, 1984.
} 
nas, en el modelado de las figura, en los procedimientos de degradación cromática de los paisajes al fondo, en los ropajes de los personajes, en las decoraciones de roleos, angelotes y ordenaciones a candelieri, o en la organización del espacio pictórico y en la relación, por ejemplo, del caballo escorzado del Apóstol Santiago de la miniatura del folio 3r. con los restantes elementos de la escena. Ahora bien, los resabios de motivos vegetales de las orlas, el predominio de los colores góticos azul y rosado, la presencia de los promotores de la obra a la manera de donantes y la representación de Felipe II entronizado sobre una cátedra gótica con cetro en la mano derecha y el orbe imperial, símbolo del poder sobre toda la Tierra ${ }^{12}$, en la izquierda, en el envés del sello de plomo que acompaña el documento, según puede verse también en la Sentencia Ejecutoria del Archivo de la Catedral de Sevilla o en la Real Cédula de Carlos V declarando las competencias judiciales entre Sevilla y Granada, demuestran cuán vivos se hallaban aún los adornos, ya epidérmicos, nórdico-flamencos en el arte español de las últimas décadas del siglo XVI. Sincretismo estilístico ya afianzado a comienzos del quinientos en obras como el Misal Rico del cardenal Cisneros ${ }^{13}$ o en no pocos libros de oraciones pertenecientes al Emperador Carlos V, cuyas preferencias por los manuscritos renacentistas con letra "redonda y en estilo clásico" quedaron manifiestas en una carta que Pietro Arentino enviaba en 1537 al calígrafo Francesco Alunno ${ }^{14}$.

-

${ }^{12}$ Así se refería al Emperador Carlos V su secretario Antonio de Valdés en la obra Diálogo de Mercurio y Calón. Véase: J. A. MARAVALL, «La visión utópica del Imperio de Carlos V en la España de su época», Carlos $V$ (1500-1558), homenaje de la Universidad de Granada, 1958, p. 63.

${ }^{13}$ J. Domínguez BordonA, Miniatura, Col. Ars Hispaniae, Vol. XVIII, Plus-Ultra, Madrid, 1962, p. 222.

${ }^{14}$ T. C. CHUBB, The letters of Pietro Arentino, Archon Books, 1967, pp. 101-ss. Citado en: J. DOCAMPO, «Imagen religiosa y devoción privada: los libros de oracio-
Como decíamos al comienzo, la Ejecutoria de Alonso de Herrera esconde tres miniaturas principales entre sus folios: una en el folio $2 \mathrm{v}$. en que se representa una Virgen de la Rosa sobre creciente lunar de clara inspiración alemana, ejecutada con toda probabilidad a partir de la reformulación de los modelos grabados al buril por Schongauer (Lehrs V, 199.40), Israhel Van Meckenen o Alberto Durero [Bartsch v. 10, 32 (53)]. De este modo, María, siguiendo la iconografía alemana que, ya desde finales del siglo $\mathrm{XV}$, se empleó para consolidar la representación de la Asunción - por ejemplo, la que Fernando Gallego realizase circa 1490 para el Altar Mayor de Santa María de Trujillo (Cáceres) - o de María Inmaculada, ya definida en miniaturas de libros iluminados como el Libro de Horas de Rouen de 1503 o el Rosarium de Felipe II, fue pintada sobre un celaje de nubes y vestida de bermellón y azurita, como correspondía a su condición de Madre del Salvador. Su rostro de facciones redondeadas - mentón chato y ojos almendrados- y su pelo - largo, rubio y rizado en múltiples hebras- van tocados por un velo hecho en albayalde. Un fondo dorado, delimitado por una mandorla mística que irradia su luz a los extremos de la miniatura confundiéndose con una intensa flama anaranjada, consuma esta representación divina, a cuyos pies se sitúan, cual donantes, Alonso de Herrera y su familia vestidos austeramente con terciopelo negro y cuellos en gola, según imponía la etiqueta de la corte de los Austrias.

La presencia de los comitentes a la manera de donantes, arrodillados, con las manos unidas y alzadas en actitud de plegaria, que subraya la individualidad de la obra ${ }^{15}$ y sitúa a sus protagonistas en un

nes de Carlos V», IX Jornadas de Arte, El arte en las cortes de Carlos V y Felipe II, Departamento de Historia del Arte "Diego Velázquez", Centro de Estudios Históricos (C.S.I.C.), Madrid, 1999, p. 218.

${ }^{15}$ P. Mogollón CANO-Cortés, «El Diurnal del 
contexto de piedad privada que no excluye, sin embargo, la exaltación pública de sus virtudes cristianas, cuenta entre sus antecedentes más antiguos la pintura aragonesa de tiempos de Pedro IV ${ }^{16}$. Tradición secular bajomedieval que, con escasas variaciones, se prolongará a numerosas representaciones del siglo XVI.

Así, en Castilla, no son pocas las obras de tiempos de Enrique IV e Isabel la Católica - pensemos en la tabla de la Virgen de los RR.CC. del Museo del Prado, durante mucho tiempo atribuida al círculo de Fernando Gallego, y más tarde considerada obra del Maestro de Miraflores ${ }^{17}$; o en la Piedad Weibel de Fernando Gallego, también conservada en la pinacoteca madrile$\tilde{n} a^{18}$ - en que los comitentes solicitan a los artistas su inmortalización junto a la imagen de Jesús Entronizado, María con Niño sobre creciente lunar, o sentada sobre una cátedra a la manera boutsiana; cuando no, junto a un santo de su devoción. Los casos son numerosísimos e imposibles de recoger aquí, si bien aquéllos del último gótico fueron, frecuentemente, concebidos bajo los principios de jerarquía y centralidad ${ }^{19}$ que

Monasterio de Guadalupe y el libro iluminado de uso privado durante la Edad Media», Norba-Arte XX-XXI, Cáceres, 2000-2001, p. 41.

${ }^{16}$ O. MARÍN CRUZADO, «El retrato real en composiciones de la pintura del siglo XVI», IX Jornadas de Arte, El arte en las cortes de Carlos V y Felipe II, Departamento de Historia del Arte "Diego Velázquez", Centro de Estudios Históricos (C.S.I.C.), Madrid, 1999, p. 116.

${ }^{17}$ A. DÍAZ PADRÓn y M. TORnÉ, «El Maestro de Miraflores, pintor de la tabla de la Virgen de los RR.CC. del Museo del Prado», Boletín del Museo del Prado, Tomo VII, no 19, enero-abril 1986, pp. 5-12.

${ }^{18}$ Sobre Fernando Gallego véanse, entre otros trabajos: P. SILVA MAROTO, Fernando Gallego, Caja Duero, Salamanca, 2004; y F. SANZ FERNÁNDEZ, Fernando Gallego y su taller en el Altar Mayor de Santa María de Trujillo (ca. 1490), Barrantes-Cervantes ed., Guadalajara, 2008 .

${ }^{19}$ A. ÁVILA, «La perspectiva en la pintura hispánica del primer Renacimiento», A.E.A., no 252, Madrid, 1990, pp. 529-553. relegaban a un segundo plano - perspectiva axiológica - a los donantes.

Frente a esta tendencia, la miniatura del folio $2 \mathrm{v}$. de nuestro códice, quizás debido a la producción seriada de este tipo de libros, bien en algún taller granadino, bien vallisoletano - pensemos en la Sentencia y carta executoria de hidalguía del bachiller Pedro de Torres $^{20}$-, presenta a los donantes Alonso de Herrera, su mujer Antonia y a sus dos hijos - bajo un esquema compositivo piramidal con proporciones similares a las que el iluminador concedió a María y Jesús. Este hecho demuestra un cambio en la concepción perspectiva de la representación, desligada ya de los formularios de lo gótico-internacional que pasaron a la pintura hispano-germano-flamenca, si bien no debemos obviar tampoco, tal cual señalábamos más arriba, la posibilidad de que esta organización carente de todo rango se debiera, según se constata en los pies de los donantes, volcados hacia las orlas, fuera de los márgenes de la miniatura, a que ésta fuese concluida con posterioridad al resto del libro, es decir, que los donantes se añadieran a un códice "concebido en serie", tan solo distinto de otros por el contenido de su texto, los retratos de sus promotores y las letras doradas que los identifican.

Esta circunstancia se confirma en otras zonas del libro en que son visibles algunas modificaciones de la estructura original, tales como en el dorado de la mandorla mística que rodea la imagen de la Virgen de la Rosa en el folio $2 \mathrm{v}$., realizado con posterioridad, según se comprueba en el velo, parcialmente tapado por el oro. De igual modo en el folio 3r., donde las letras inmediatamente inferiores a la escena en que se representa a Santiago Matamoros

\footnotetext{
${ }^{20}$ N. LÓPEZ MARTín, «Los Reyes en su corte», op. cit., p. 126.
} 
fueron ejecutadas con posterioridad a la miniatura, dado que se sitúan sobre ésta.

Estos y otros hechos demostrarían, en nuestra opinión, que la producción de estos libros se haría en serie, es decir, que se compraban ya iluminados para, posteriormente, añadirles el texto de una ejecutoria, y no al revés, como ha venido considerando gran parte de la historiografía.

La segunda miniatura, que representa a Santiago Matamoros según el modelo también de origen alemán representado en la Ejecutoria de Hidalguía de Francisco de Cuenca Utrera, del año 1602, resuelta en la Chancillería de Granada (Museo de Bellas Artes de Sevilla), es una escena de fuertes contrastes cromáticos, que el autor consigue con una gama de pigmentos rojos, verdes y azules que se encuentran y dialogan violentamente; así como de un gran dinamismo y una cuidada ordenación compositiva, como se comprueba en el impetuoso movimiento del caballo, escorzado y encabritado, en la torsión de tres cuartos del agareno personaje situado bajo Santiago, o en el grupo de alabarderos de la derecha.

Por último, la imagen del folio 44r. representa a Felipe II según el esquema característico de los retratos flamencos busto recortado hasta las manos y cabeza de perfil ligeramente girada - bajo el ductus de una "P". El monarca, como corresponde a su condición de soberano de España, adopta una serie de formulismos y convencionalismos que revisten su imagen de un decoro renacentista, tales como la capa de armiño, el collar de la Orden del Toisón de Oro o una expresión altiva y distante, dotada de la gravedad propia de su cargo. Su cabeza aparece tocada y su barbilla, afilada, cubierta de una barba cana y ajustada a una gola.
EL CONTORNO, EL MODELADO, LA LUZ Y EL COLOR EN LAS MINIATURAS.

El contorno, delimitado por un trazo grueso y visible en la fase de color, se realiza normalmente con el mismo pigmento que ornamenta la zona de la figura o del objeto inmediatamente a éste adyacente, de manera que varía del rojo o verde, al amari1lo, azul o negro. Este recurso consigue que la percepción de la miniatura o de una parte principal de su modelado se diluya sutilmente entre los colores del fondo geométrico en que se integra, a pesar de los violentos contrastes que produce, por ejemplo, el encuentro entre el bermellón y el oro, tal cual puede comprobarse entre el manto de la Virgen y la mandorla mística en el folio $2 v$. No obstante, las zonas del cuerpo que aparecen desnudas, manos y caras de los donantes del folio 2v. o de Felipe II en el folio $44 \mathrm{r}$., y el niño Jesús del citado folio $2 \mathrm{v}$., quedan claramente delimitadas por una línea gruesa de color sombra. En otras ocasiones, caso del rostro ensangrentado y de semblante temeroso del infiel que tendido sobre el suelo contempla la victoria del Apóstol Santiago, los rasgos físicos de su rostro - cejas, barba y contorno de carafueron pintados con negro carbón, señalando así las necesarias diferencias raciales que habrían de identificarlo y reconocerlo por oposición a sus congéneres cristianos. Aquí subyace una vez más la tradición aquiniana seguida en el arte cristiano medieval, especialmente en las manifestaciones pictóricas, que asociaba la idea de belleza a lo bueno y la fealdad, o más concretamente la diferencia racial, por oposición, a lo malo.

Esta misma fase de modelado se completa con un trazo grueso de manchas de color intenso, siempre del mismo tono del ropaje, vestidura o paisaje, al que sirven de apoyo para la construcción del volumen. En ocasiones, caso del caballo del Apóstol en la miniatura del folio $3 r$., este modelado es resuelto con agrupaciones de líneas finas, 
rectas y paralelas, escasamente espaciadas. La posibilidad de que este trazo, resuelto con toda probabilidad a pluma, se apoye sobre un dibujo previo, hoy oculto por la imagen visible e imposible de advertir, por tanto, sin la preceptiva luz infrarroja, es muy alta, dado que era un procedimiento habitual entre los miniaturistas ${ }^{21}$. Este dibujo, una vez concluidos los aspectos generales de la representación, por tanto, consecuencia de una fase de preparación que hubiera ya resuelto los problemas de correcciones y arrepentimientos, sería calcado en seco sobre la vitela, bien, como parece más probable, por un sistema de traslación a modo de falsa estampación, bien mediante una sinopia trasladada por puntos, como puede observarse en las incisiones que delimitan el becerro superior del tercer cuartel del escudo de armas del comitente en la parte inferior del folio $2 \mathrm{v}$.

Sea como fuere, lo cierto es que el desconocido iluminador de nuestro códice prefiere apoyarse en la gradación de intensidades cromáticas antes que en la precisión y delimitación de los contornos para el plegado de ropajes y vestiduras, y sugerir así el volumen y el espacio. $\mathrm{Y}$ es aquí, donde, a pesar del influjo nórdico y flamenco perceptibles en otros aspectos de su obra, el artista se manifiesta fiel a los procedimientos estilísticos de la pintura española del último Renacimiento.

En lo que a la gama cromática se refiere, rica y variada, destacan el negro carbón, el albayalde o blanco de plomo, el bermellón, la azurita, el verde y el amarillo. Ésta la completan el oro y la plata aplicados en finísimas láminas sobre una base cuya composición desconocemos, pero que muy bien podría estar formada por varias capas

${ }^{21}$ A ello hacen referencia diversos textos históricos, como el tratado napolitano De arte illuminadi conservado en la Biblioteca Nazionale de Nápoles o el Arte de la Pintura de Cennini. de cola rebajada y de clara de huevo batida con agua ${ }^{22}$.

En lo que al empleo de la luz se refiere, llama la atención el desigual tratamiento concedido por el artista a las miniaturas de los folios $2 \mathrm{v}$. y $3 \mathrm{r}$., dado que si en la primera - Virgen de la Rosa sobre creciente lunar - las intensidades lumínicas provocadas por la mandorla mística de María y su fondo de oro no se reflejan en los restantes elementos de las escena -donantes-, quizás, como señalábamos anteriormente, porque la presencia de éstos no estaba prevista en un principio, o sencillamente porque el artista se ajusta a la concepción metafísica del mundo gótico y no a la materialización física de la luz renacentista; en la imagen del Apóstol, en cambio, la degradación cromática conseguida con sutiles toques de azul en el caballo en corbeta y de albayalde en el perfilado de la flora de las orlas, y la perspectiva aérea del fondo, demuestran su conocimiento de los recursos propios de la pintura renacentista.

\section{CONCLUSIONES.}

De cuanto se ha mencionado hasta aquí puede deducirse: que la Ejecutoria de Hidalguía de Alonso de Herrera se ajusta a los modelos realizados en los talleres castellanos y andaluces la segunda mitad del siglo $\mathrm{XVI}$, de tal manera que los temas de las miniaturas, la decoración de las orlas y la organización y ordenación de sus páginas responden a una tradición artística consolidada y a una tipología producida en serie. Circunstancia que si bien no resta valor artístico a la obra, la sitúa a la misma altura de los numerosos trabajos de parecida factura conservados en nuestro país. También, que el orden de ejecución de las distintas fases que fueron necesarias para su conclusión demuestra cómo Alonso de Herrera

\footnotetext{
22 Según propone C. MALTESE, Las técnicas artísticas, Manuales Arte Cátedra, Madrid, 1995, p. 309.
} 
compró en algún taller, probablemente castellano - dada la mayor similitud de la obra, especialmente en lo referido a la encuadernación, con otras ejecutorias salidas de la Chancillería de Valladolid - , un docu-

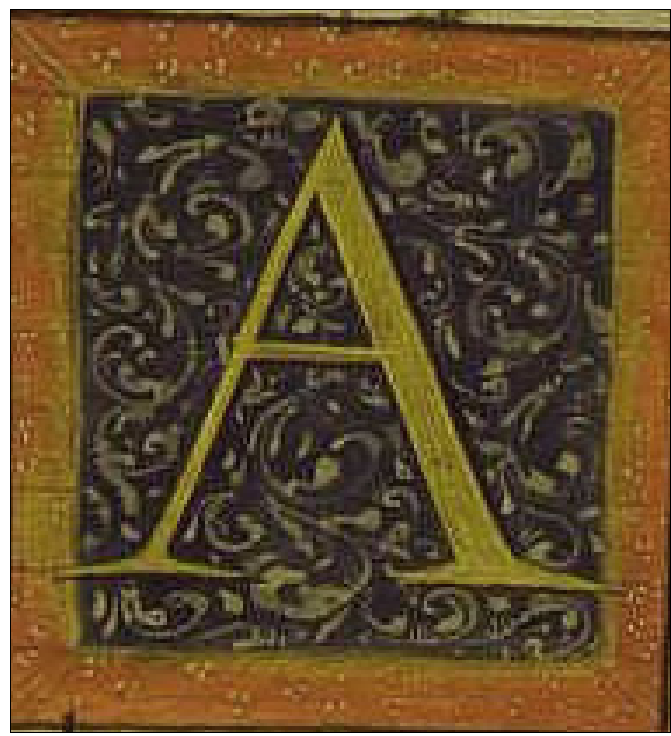

- Lám. 1. Capital en oro sobre fondo azul y bordura bermellón.

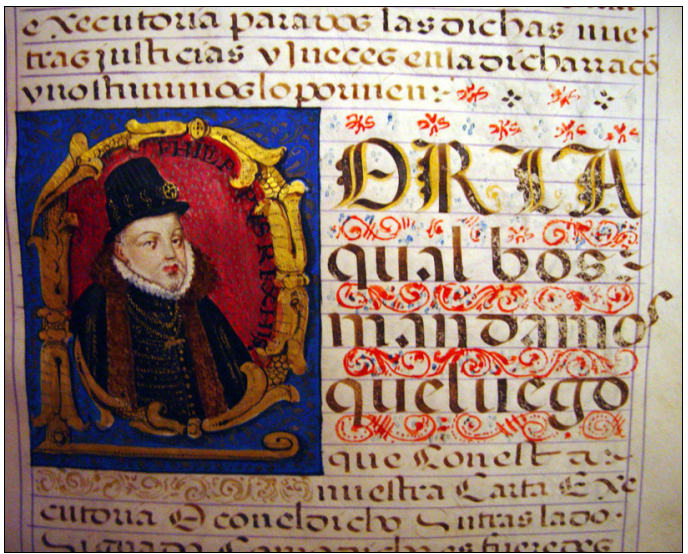

- Lám. 3. Felipe II bajo el ductus de la capital «P». mento parcialmente iluminado al que ordenaría añadirle su retrato y el de su familia, sus armas y el texto del pleito librado en Granada.

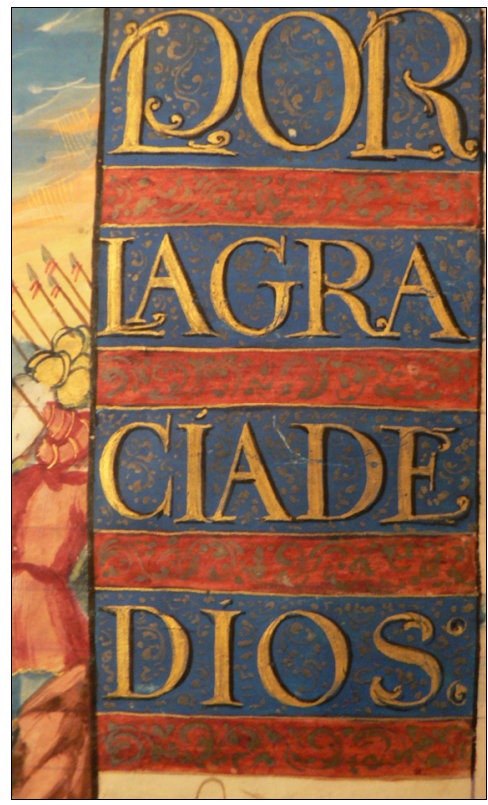

- Lám. 2. Folio, 3r (bis).

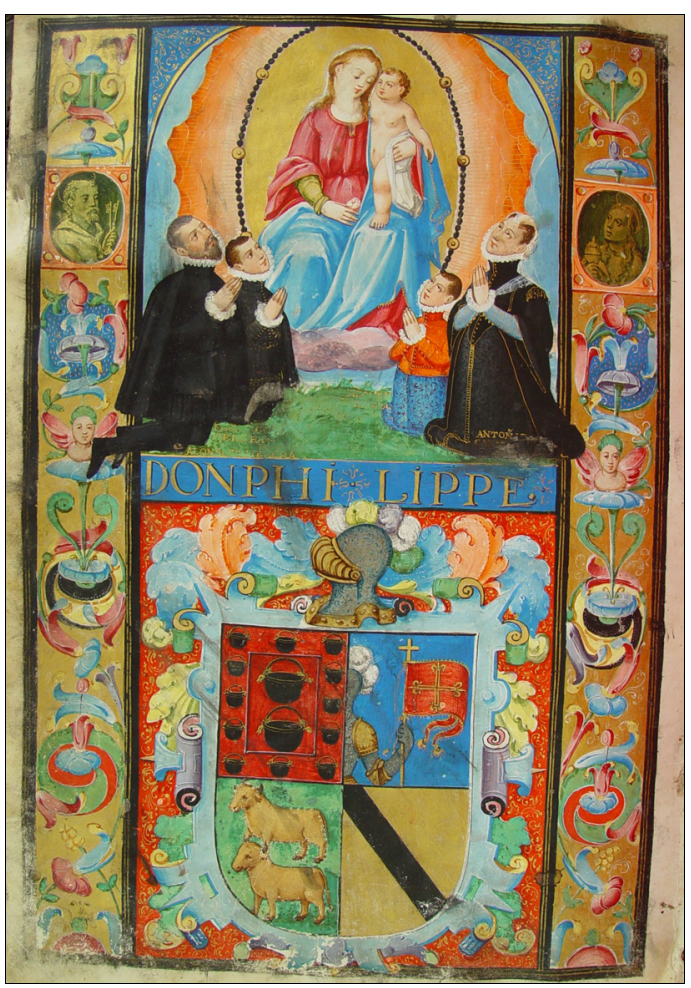

- Lám. 4. Folio, 2v. 


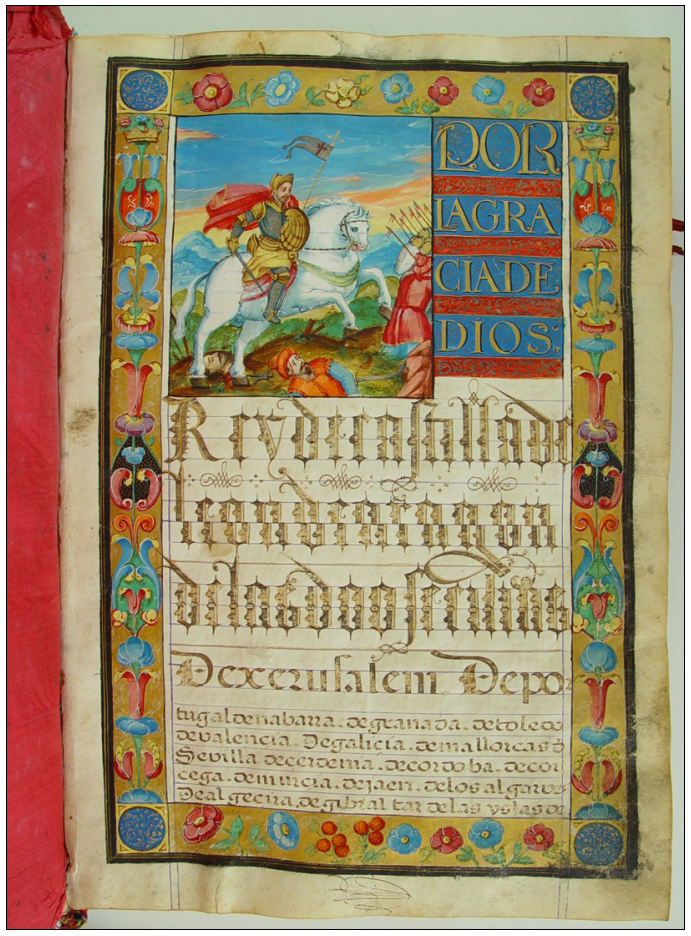

- Lám. 5. Folio, 3r.

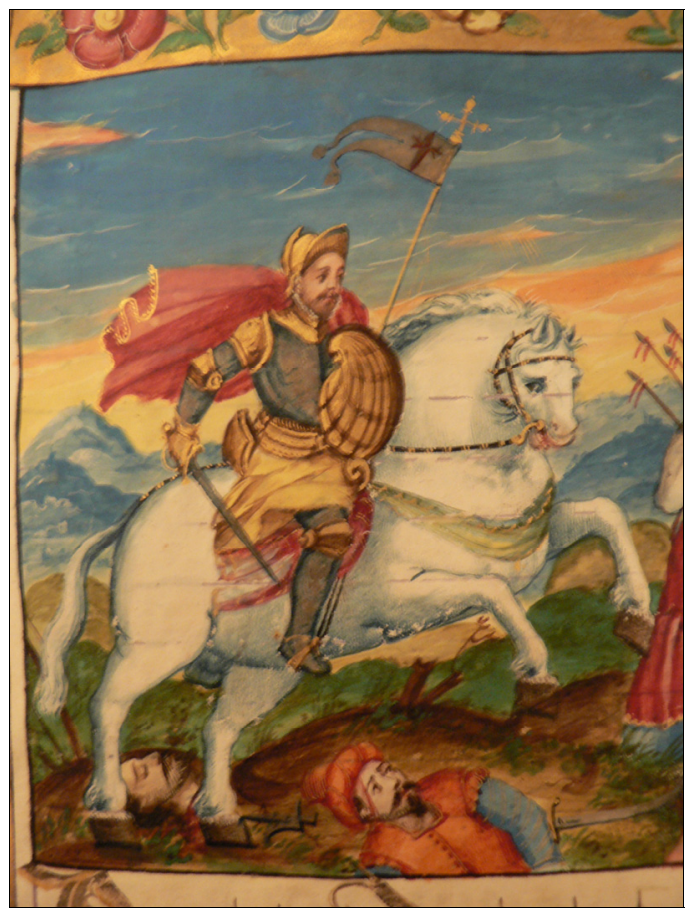

- Lám. 7. Santiago a Caballo, folio, 3r.

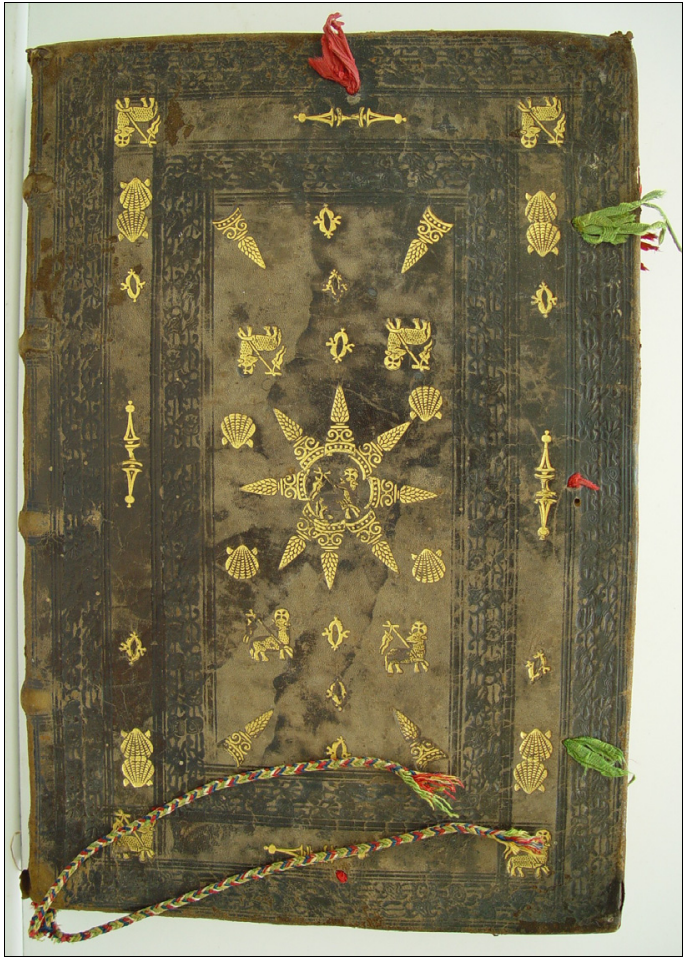

- Lám. 6. Encuadernación en piel con decoración floral incisa "en blanco" y piñas pinjantes, conchas y Cordero Místico en oro.

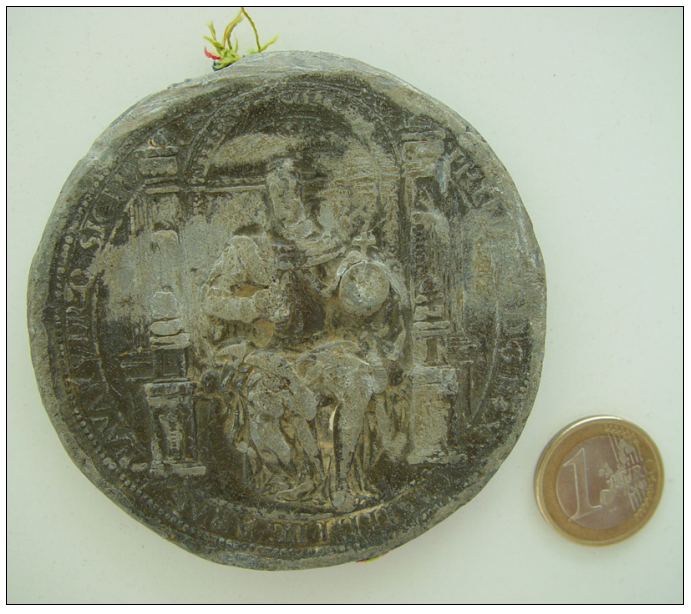

- Lám. 8. Sello de Plomo con Felipe II entronizado. 


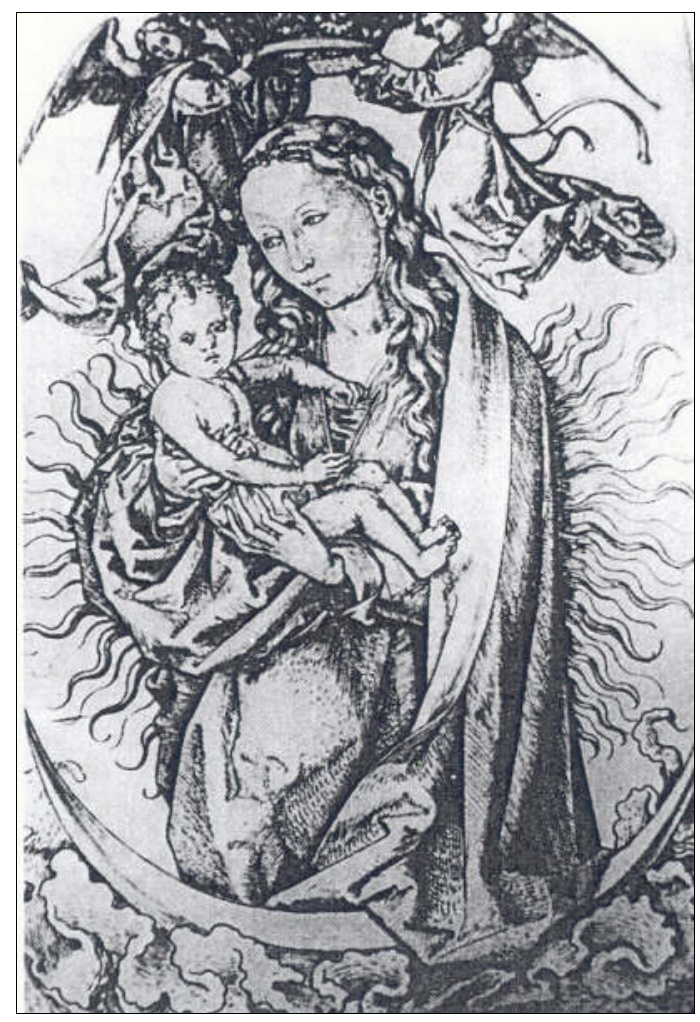

- Lám. 9. Virgen sobre Creciente Lunar. Martin Schongauer.

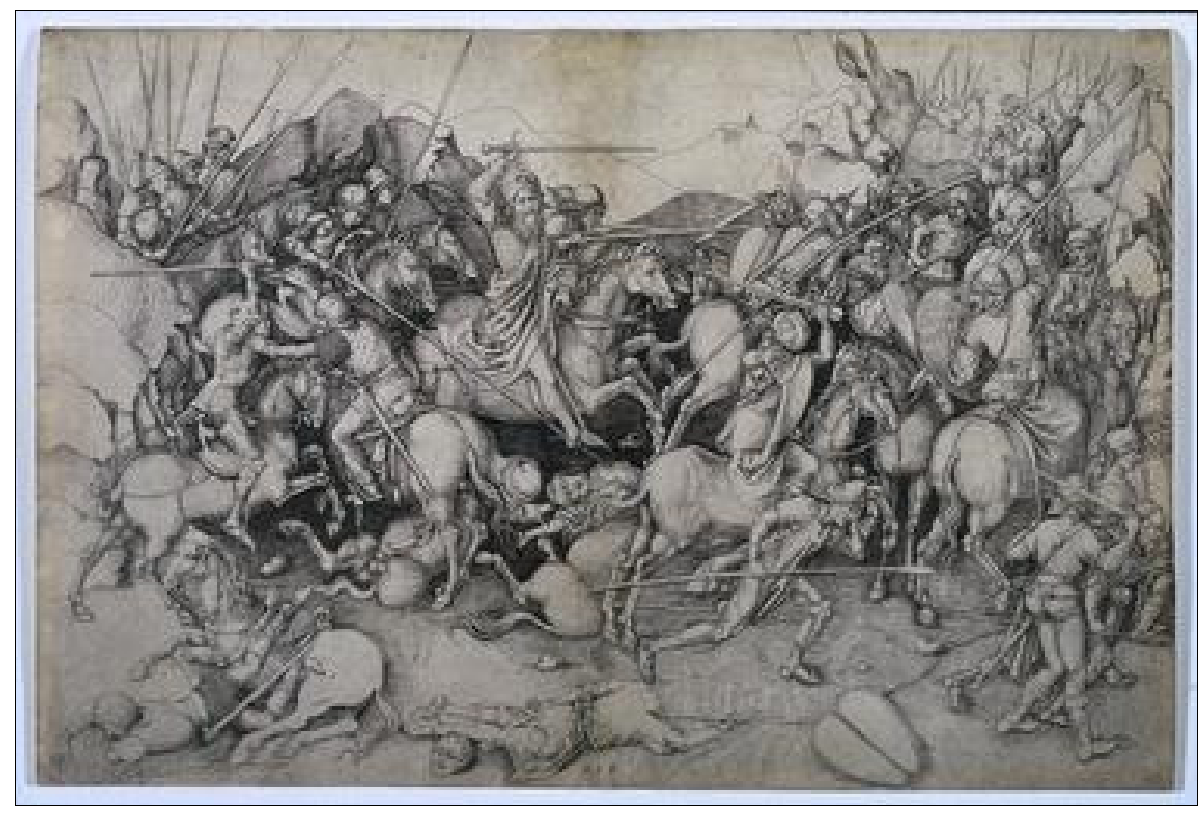

- Lám. 10. Santiago Matamoros. Martin Schongauer. 